\title{
Climate Change Impact on Vegetation Dynamics in Tensift Region, Morocco
}

\author{
Y. Akensous, A. Al Sabri, S. Al-Akad, and M. Hakdaoui
}

\begin{abstract}
Tensift region is known by an arid and semi-arid climate. The city of Marrakech, experience an important temporal variability in rainfall and an increasing trend of temperature during the last five decades. However, the evolution of rainfall is more contrasted by a downward trend in Marrakech, it is also distinguished by alarming clues of global warming, like the number of hot days and heat waves. This paper evaluates the effect of climate change on Vegetation cover (evaluated by NDVI) in the Tensift region, Morocco. Temperature, rainfall data, and vegetation cover were used in this analysis. The effect of climate change on vegetation was studied using a linear regression analysis method, to explore the relationship between vegetation dynamics and climate factors (the trend of vegetation dynamics for the years between 1973 -2019). Analysis of annual data, for the temperature and vegetation cover shows a low regression coefficient value of 0.3057 and, rainfall and vegetation cover analysis show regression coefficient value of $\mathbf{0 . 7 0 2 4}$. Monthly periods analysis showed that the most important period is the one between December and May where the regression coefficient value is 0.6568. In more details the period between March and May shows regression coefficient value of 0.4685 , the period between December and February shows regression coefficient value of 0.434, the period between September and November shows regression coefficient value of 0.0734 . The study reveals that, rainfall is significantly related with vegetation cover, especially the period between December and May, more than the temperature does in Tensift region.
\end{abstract}

Index Terms-Tensift region, climate change, vegetation dynamic, correlation.

\section{INTRODUCTION}

Climate indicates the typical weather conditions of a specific region and climate change implies extreme variability in the frequency and extent of events Climate parameters include temperature rainfall humidity etc. Given that any change in one parameter directly or indirectly affects the other parameters and in turn it also unbalances the ecology of the physical environment in the Tensift region of Morocco [1].

The climate has a dominant impact on the natural distribution of vegetation. Fossil records and observed trends have shown that climate change has a profound influence on

Manuscript received February 3, 2021; revised April 8, 2021.

Y. Akensous, M. Hakdaoui, and S. Al-Akad are with the Department of Geology, Laboratory of Applied Geology, Geomatics and Environment, Faculty of Sciences Ben M'sik, Hassan II University, Casablanca, Morocco (e-mail: akensous1990@gmail.com, hakdaoui@gmail.com, su.sultan12@gmail.com).

A. Al Sabri is with Laboratory of Engineering and Materials, Faculty of Sciences Ben M'sik, Hassan II University Casablanca, Morocco (e-mail: a.alsabri2011@gmail.com). the distribution of vegetation. It is therefore inevitable that climate change will have a significant impact on the vegetation distribution at global level [2].

Vegetation is one of the most critical elements of terrestrial ecosystems [3]-[5]. Spatio temporal variations in vegetation growth can affect the Earth's carbon cycle and other biochemical processes [6], thus explaining why the study of its dynamics is an emerging problem in the field of analysis environmental Vegetation changes are constantly affected by differences in factors such as precipitation temperature and human activities [7], [8]. The dynamics of vegetation change is an important indicator for assessing these eco environmental changes Chronological land cover data are often used to detect dynamic changes in vegetation and to extract patterns and patterns of change [9].

Vegetation indices such as the Normalized Difference Vegetation Index NDVI are important characteristic parameters for revealing the characteristics of surface vegetation Some results from previous research confirm that changes in NDVI time used for photosynthesis NDVI is also very sensitive to the physical characteristics of vegetation angles of observation of collectors solar radiation and different backgrounds of the ground [10]. Several vegetation properties such as the length of the growing season the date of the start of greening and the date of maximum photosynthetic activity can be derived from the NDVI time series to monitor changes in vegetation [11]-[13].

The warming of the climate system is unequivocal and the change in climate variables for example precipitation and temperature will ultimately have a great impact on plant cover and agricultural practices CCP 2013 The study of vegetation's response to climate change has received considerable attention over the past two decades [14], [15]. In the literature the Normalized Difference Vegetation Index NDVI has been frequently used as a reliable index for monitoring ground cover and vegetation variability [15]-[17] and study the response of vegetation to climate change on a regional, continental and global scale over the past two decades [18], [19].

With population growth and human activities, there is great pressure on arable land, water, energy and biological resources to provide an adequate supply of food while maintaining the integrity of our ecosystem. Changes in land use are taking place due to rapid urbanization, changes in river systems, the effects of shifting cultivation, the spread of erosion and desertification. Change in land use is directly linked to the hydrological cycle and any change in land use and shifting cultivation is the main cause of large-scale changes in the associated ecosystem. Studies on climate change generally tend to analyze only the climatic parameters. In Tensift regions, the climate and vegetation appear to have 
reacted to past global climate.

Furthermore, the development of the vegetation cover management depends on the amount of rain received by the area and, in turn, affects the environment. This implies that the impact of climate change on vegetation specially rain, is important in the planning of the area [20]. Precipitation and temperature significantly affect the distribution of vegetation. Vegetation requiring humidity, rain and favorable temperatures, it can characterize the regional weather.

For large areas with vegetation, the Normalized Difference Vegetation Index (NDVI) method is the best suited when the analysis is performed using past or present images without ground truth data. Changes in vegetation and land cover are closely correlated to changes in precipitation which, in turn, have feedback on the regional climate. Aerosols alter the sunlight that reaches the vegetation, affecting the assimilation and transpiration of carbon. Over the past two decades, Remote Sensing (RS) and Geographic Information System (GIS) techniques have been widely used to detect the type of change, the location of change and the quantification of change in land use / land cover. In particular, image analysis by RS can provide a direct record of the short / long term impact on land use / land cover in the past or the past [1], [21], [22].

The potential of Landsat image data is to provide an accurate classification of changes in land cover over time [23]. In addition, change detection via RS means that the change in spectral signatures is proportional to the change in land cover. The detection of changes can be accurately determined using GIS due to its high volume of spatial and non-spatial data processing capabilities [24]. Precipitation and temperatures vary and atmospheric $\mathrm{CO}_{2}$ concentrations increase due to anthropogenic activities contributing to climate change [22], [25]-[27]. The forest cover development depends on the amount of rain received by the area and it, in turn, affects the environment [28].

As long as the vegetation requires moisture, rain and favorable temperatures, it may characterize the regional weather. The precipitation and temperature significantly affected the distribution of vegetation. The Normalized Difference Vegetation Index (NDVI) [29], [30] method is better suitable, for large areas comprising vegetation, where analysis is carried out using either past or present images with no ground truth data. Vegetation and land cover changes are closely correlated with precipitation changes which, in turn, have feedback on the regional climate. Aerosols alter sunlight that reaches vegetation, affecting carbon assimilation and transpiration [1]. In the past two decades, Remote Sensing (RS) and Geographical Information System (GIS) techniques are used extensively to detect the type, location and quantification of changes in land use/land cover [31]. Notably, image analysis by RS can provide a direct record on long and short term impact on land use/land cover. The potential of Landsat image data is to provide an accurate classification for land cover changes over time [23]. Also, the change detection through RS means the change in spectral signatures commensurate with the change in land cover. Change detection can be precisely determined using GIS due to its high volume of spatial and non-spatial data handling capabilities [24].
Therefore, study on effect of climate changes on vegetation area is essential to identify the ecosystem functions in the Tensift region for proper planning and management. It is evident from the recent review of literature that only a little (for example Babqiqi 2014, Bensalem 2014) research work has been directed towards the study of the effects of climate change on forest and vegetation cover in Morocco regions, especially the region of Tensift [32], [33]. However, this study attempts to (a) estimation of total vegetation cover area over Tensift using satellite data, and (b) to evaluate the impact of climate change on vegetation.

\section{MATERIALS AND METHODS}

\section{A. Description of the Study Area and Context}

The Tensift region, located in west central Morocco (Fig. 1), has an arid to semi-arid climate overall [34]. It is undergoing a range of climate change and significant environmental variations. The climatic trends observed in the cities of Marrakech, through the study of meteorological data since 1961, have made it possible to identify a clear trend towards higher temperatures and lower precipitation [35].

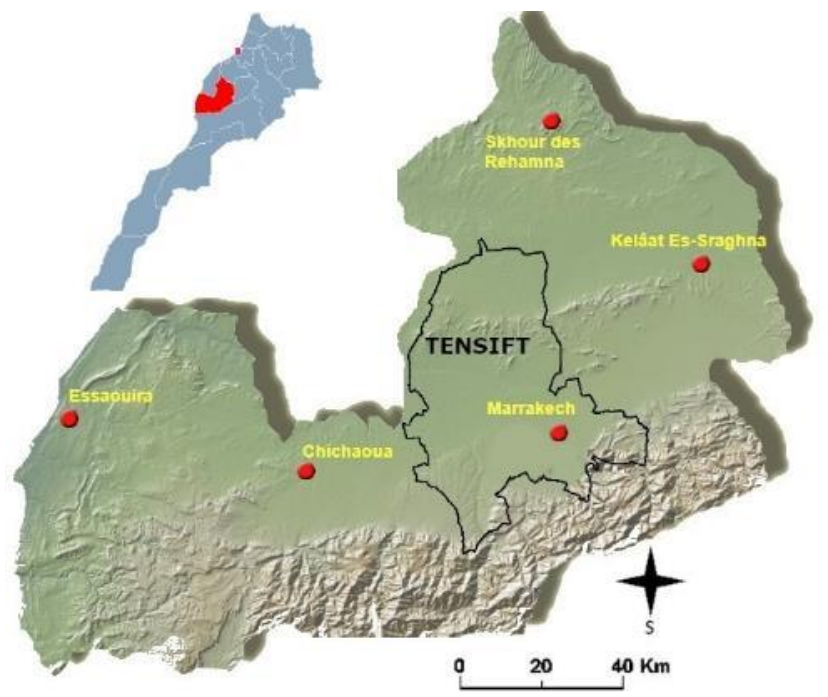

Fig. 1. The study area

In addition, statistical tests by Pettitt, Hubert, Buishand and Lee and Heghinian revealed changes in the mid-1970s. Period after which a precipitation deficit (up to -30\%) was recorded [34]. This paper aims to bring out the elements that characterize the climate variability of the Tensift region, study its recent evolution through temperature and precipitation and make correlation with vegetation, using appropriate forecasting models.

\section{B. Development of the Model}

In this study, temperature, rainfall, vegetation cover data were used to establish their relationship using the same method used by Palmate et al. (2017) in his study on the vegetation of the Indian Betwa basin. This method is the linear regression which is a simple and very efficient method, that was never used in studying the climate factors impact on vegetation dynamic in Tensift region, known that it is affected by climate change. The climate data described in terms of temperature and rainfall were used to detect the 
climate condition and for vegetation cover detection, satellite imagery of Landsat 4-5 TM (Thematic Mapper) and Landsat 7 ETM? (Enhanced Thematic Mapper) plus type data was downloaded from the USGS website: http://glovis.usgs.gov/ for the years 1973 to 2019. All the Images existed in the platform were selected for spring season exhibiting minimum interference of cloud cover. Fig. 2 shows the flowchart of methodology adopted in this study the correction of satellite images includes radiometric correction based on the radiance and geometric corrections based on the digital number, were performed for all the images. Radiometric correction used to remove sensor or atmospheric noise and to represent accurate ground conditions in an image (Zhang et al. 1999). Also, geometric correction used to remove distortion prevention by the rectification of an image (Wie and Stein 1977). In this study unsupervised classification by using NDVI was considerate to extract the vegetation cover area.

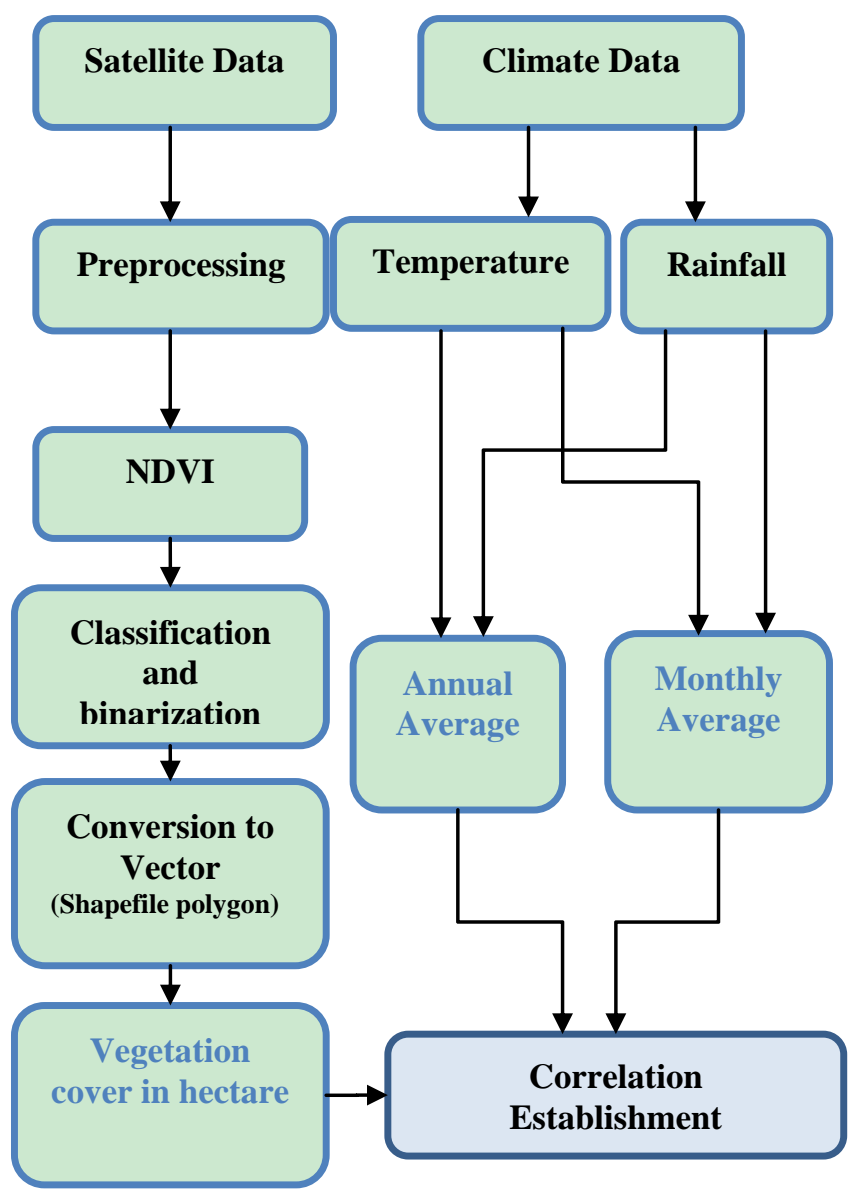

Fig. 2. Flowchart of methodology used for establishment of relationship.

The NDVI method was used for monitoring temporal changes in vegetation. It has been used to prepare spectral vegetation indices which separate green vegetation using

In this study, vegetation cover class includes: the forest cover, the agricultural area, as well as all other types of plants area (Fig. 3). As per imagery seasonal dates, seasonal averages of rainfall and temperature were derived for the respective years. Regression analysis method was used to describe the relationship between two dependent variables (forest cover and vegetation) and two independent variables (temperature and rainfall) (Fig. 2). The relationships amongst vegetation cover and climate factors for the period
1973-2019 were assessed using linear regression (simple method uses one variable and test the response of another variable to it), with a focus on the r-square values and correlation coefficient. The analysis was performed by using the data of average yearly, monthly of rainfall and temperature, as well as vegetation cover in hectare. This technique has been used to investigate relationship between climates variables with vegetation cover.

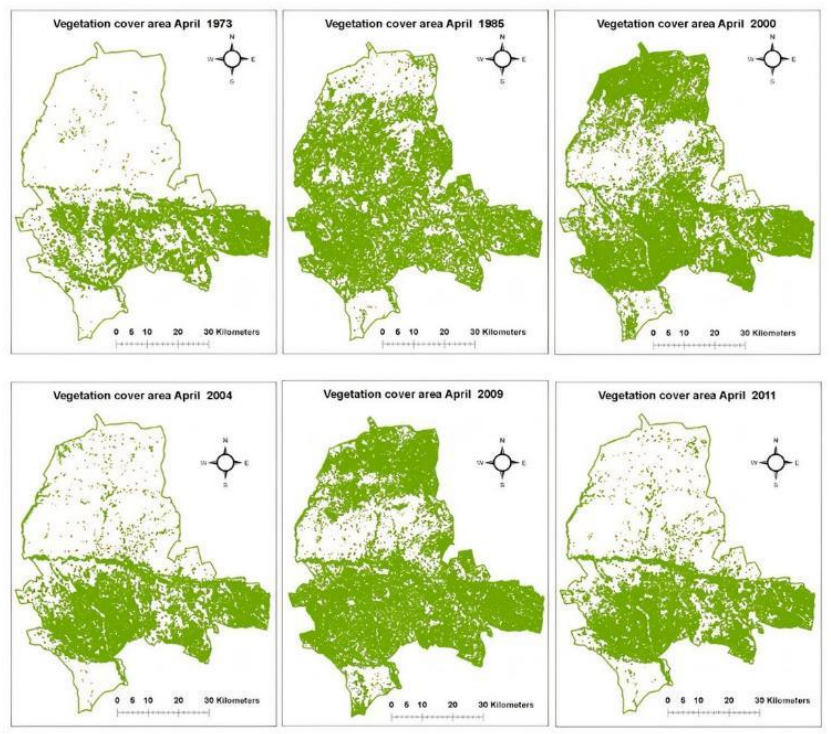

(a). Cover vegetation during the period 1973 and 2011

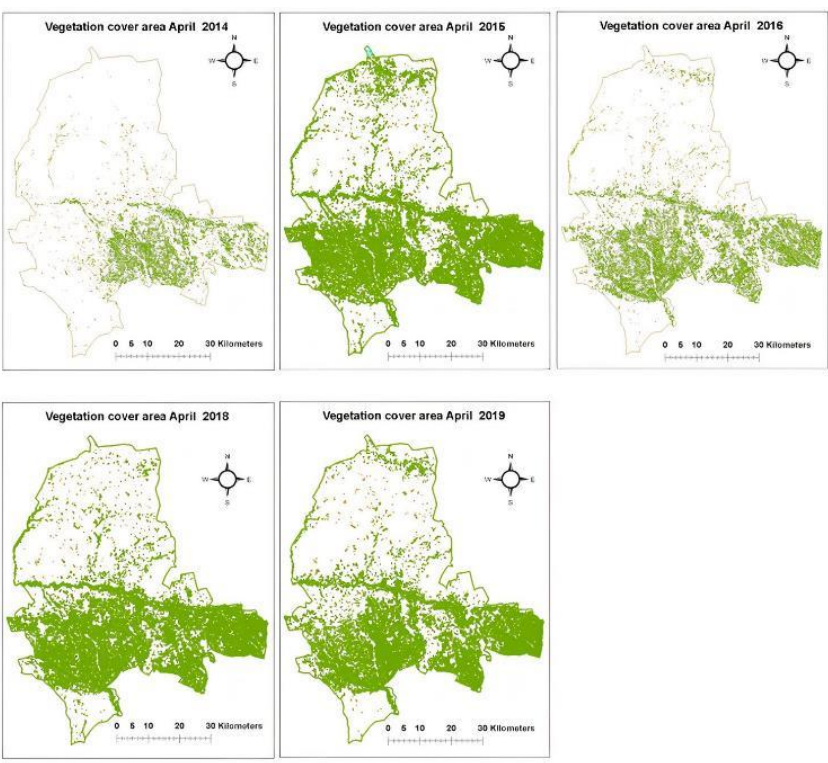

(b). Cover vegetation during the period 2014 and 2019

Fig. 3. Vegetation Cover; (a). Cover vegetation (1973 - 2011); (b). Cover vegetation (2014 - 2019).

\section{RESUlTS AND DisCUSSION}

The results obtained from analysis of the climatic data and satellite data are discussed in this section. Fig. 4 and 5 show the regression values between seasonal averages of temperature $\left({ }^{\circ} \mathrm{C}\right)$, rainfall $(\mathrm{mm})$, and vegetation cover (hectares). Further, climatic data onto 14 different years (1973, 1985,1996,1998,1999, 2001, 2004, 2007, 2009, $2010,2015,2016,2018$ and 2019) were used to calculate their annual and monthly averages. Using satellite data, the 
vegetation cover area was obtained by image classification using NDVI index.

\section{A. The Annual Data}

Fig. 5 show graphical relationship between the mean values of temperature $\left({ }^{\circ} \mathrm{C}\right)$, rainfall $(\mathrm{mm})$ and vegetation cover (hectares). The Fig. 5 (a) depicts the graphical relationship between temperature and vegetation cover, the regression analysis shows a lower regression coefficient value 0.3075 (The coefficient of correlation $r$ is the square root of R2 presented in the graphical results) this $r$ value indicates a poor correlation between temperature and vegetation cover. Similarly the Fig. 5 (b) depicts the graphical relationship between rainfall and vegetation cover, the regression analysis shows a moderate regression coefficient value of 0.7024 witch indicates that there is an exhibited relationship between rainfall and vegetation cover.

(a) September to november

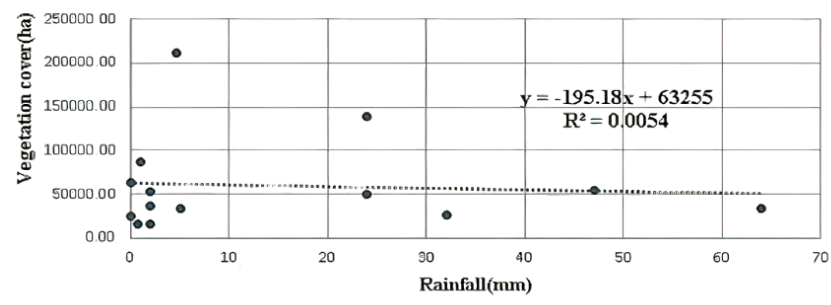

(b) March to May

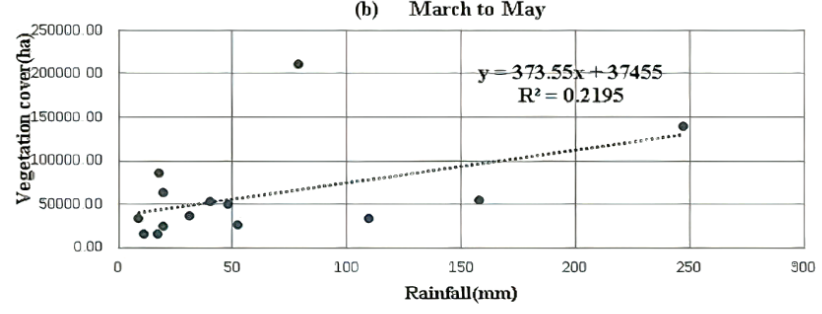

(c) December to february

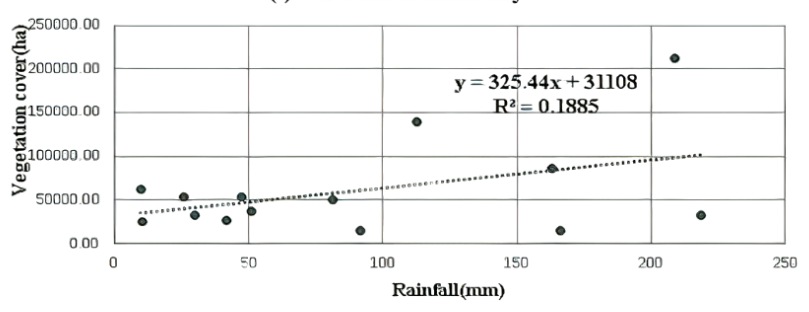

(d) December to may

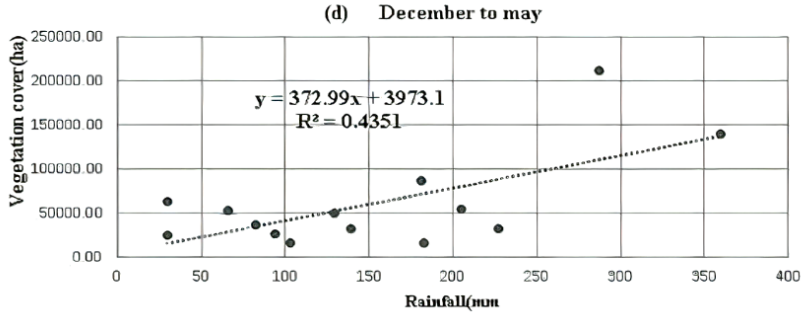

Fig. 4. Graphical relationship between Vegetation cover and rainfall.

\section{B. The Monthly Periods Data}

In the previous section, we noticed that the rain has a significant impact on vegetation. In order to know in more detail, the impact of rainfall on the Vegetation cover, we did it for different periods of the year when the rain is present, for example, the period going from the end of spring to the end of summer is not taken into consideration because the rain is missing during this period. Furthermore, the period when there is interesting rainfall is that of December to May so it is the one that affects mainly the plant cover of Tensift.

Table I shows the Description of relationship between Vegetation cover and rainfall for different periods. Relationship between two variables associated with their changes is analyzed graphically and presented in Fig. 4 depicts the graphical relationship between climatic variable and vegetation cover.

TABLE I: DESCRIPTION OF RELATIONSHIP BETWEEN VEGETATION COVER AND RAINFALL

\begin{tabular}{lll}
\hline \hline No. & Monthly Periods & Correlation value $r$ \\
\hline 1 & September to November & 0.0734 \\
2 & March to may & 0.4685 \\
3 & December to February & 0.4341 \\
4 & December to may & 0.6596 \\
\hline
\end{tabular}

Regression analysis between rainfall and vegetation cover shows a low regression coefficient value of 0.0734 for the period between September to November (Fig. 4 (a)).The period between March to May shows a moderate regression coefficient value of 0.4685 (Fig. 4(b)).the period between December to February shows a moderate regression coefficient value of 0.4341 (Fig. 4 (c)) .the period between December to May shows the highest regression coefficient value of 0.6596 (Fig. 4 (d)) and exhibited a significant relationship.

\section{DISCUSSION}

The results obtained from the annual data analysis showed a significant relationship between rainfall and vegetation cover in Tensift region, but in terms of temperature and vegetation cover, there is a medium relationship between them. The temperature responded inversely to the vegetation cover for the study area, which means that a rise in temperature reduced moisture availability of soil and decrease in water requirement of crop resulted in low vegetation growth. Because of this analysis, the impact of rainfall on spring vegetation is more significant than that of temperature. It is for this reason that we focus on detecting the impact of rainfall from different periods of the year on spring vegetation. For the period between December and May, water requirement of plants is sufficiently fulfilled due to monsoon rainfall. Rainfall helps to retain adequate moisture availability in soil so that the plant roots can easily extract water from soil for their growth. Hence, relationship between rainfall and vegetation cover resulted high regression coefficient which prevails increase in vegetation cover for spring vegetation in Tensift region. At the end Relationship of rainfall and vegetation cover is directly related for the Tensift region.

The Regression analysis of the temperature dynamics shows that it is increasing, and this will affect the vegetation which is in a reversed regression relation with the temperature therefore in the future years as long as the temperature is increasing the vegetation will be decreased. Fig. 6 shows that the rainfall for the period from 1961 to 2007 
is decreasing and it is the same for the period taken in this analysis, same case for the vegetation cover which means that as the rainfall is decreasing the vegetation will also according to the analysis.
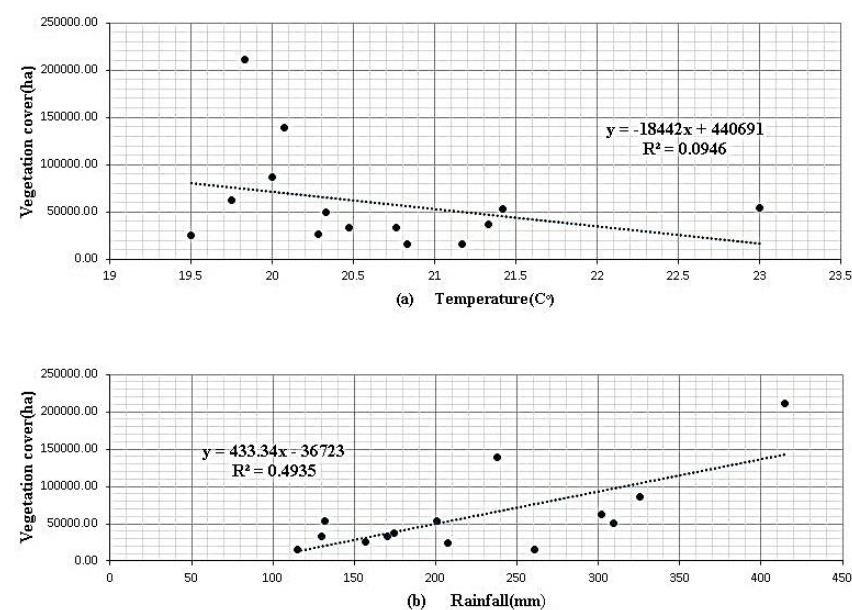

Fig. 5. Graphical relationship: (a) between Vegetation cover and temperature, (b) between Vegetation cover and rainfall
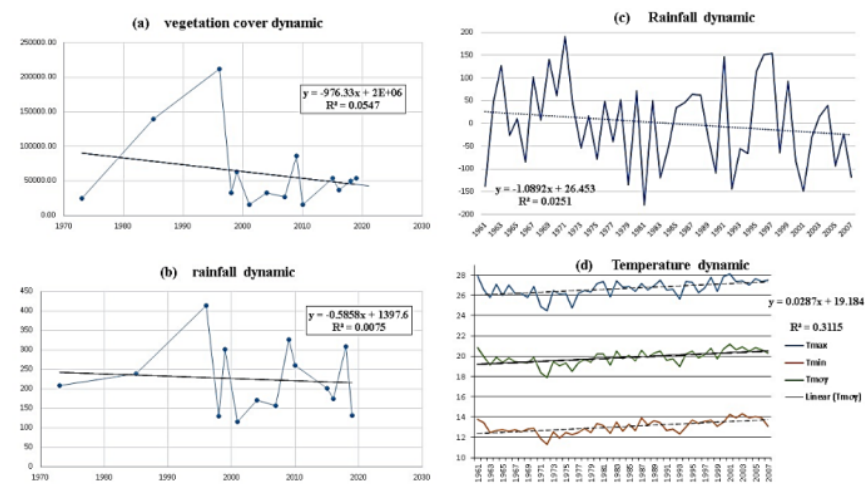

Fig. 6. Graphical Vegetation, rainfall and temperature dynamic.

\section{CONCLUSIONS}

At the end of this study, conclusions were drawn by studying and analyzing the effect of climate changes on vegetation. For annual data, a regression analysis of the temperature over the vegetation cover shows the regression coefficient values of 0.3075 . However, the regression analysis for rainfall over the vegetation cover shows the value of the regression coefficient of 0.7024 . Vegetation cover is closely related to rainfall more than temperature does for the annual data. Rainfall is significantly associated with vegetation cover through statistical analysis, but for the temperature it graphically illustrates that there is a slight association. It is for this reason why we had been concentrated on rainfall for monthly data period. For monthly data period, a regression analysis of the rainfall for different periods over the vegetation cover shows the regression coefficient values of 0.0734 for the period between September and November, 0.4685 for the period between March and May, 0.4341 for the period between December and February, 0.6596 for the period between December and may. Furthermore, the rainfall for the period between December and May showed a significant positive response to the vegetation cover.

The study revealed that the effect of climate is important on vegetation cover especially the rainfall precisely for the period between December and May, but for the long term change the temperature has also an effect on vegetation, which can be monitored by the use of satellite data of the Tensift region

\section{CONFLICT OF INTEREST}

The authors declare no potential conflict of interest.

\section{AUTHOR CONTRIBUTIONS}

Y. Akensous. conceived of the presented idea; collection of the data; performed the analysis and wrote the paper. A. Al Sabri. contributed data. M.Hakdaoui. and S. Al-Akad. Verified the analytical methods. M.Hakdaoui. supervised the findings of this work. All authors discussed the results and contributed to the final manuscript.

\section{REFERENCES}

[1] S. S. Palmate, A. Pandey, D. Kumar, R. P. Pandey, and S. K. Mishra, "Climate change impact on forest cover and vegetation in Betwa Basin, India,” Appl. Water Sci., vol. 7, no. 1, pp. 103-114, Mar. 2017, doi: 10.1007/s13201-014-0222-6.

[2] I. Rashid et al., "Projected climate change impacts on vegetation distribution over Kashmir Himalayas," Clim. Change, vol. 132, no. 4 , pp. 601-613, Oct. 2015, doi: 10.1007/s10584-015-1456-5.

[3] R. Liu, R. Shang, Y. Liu, and X. Lu, "Global evaluation of gap-filling approaches for seasonal NDVI with considering vegetation growth trajectory, protection of key point, noise resistance and curve stability," Remote Sens. Environ., vol. 189, pp. 164-179, Feb. 2017, doi: 10.1016/j.rse.2016.11.023.

[4] A. Zhao, A. Zhang, C. Lu, D. Wang, H. Wang, and H. Liu, "Spatiotemporal variation of vegetation coverage before and after implementation of Grain for Green Program in Loess Plateau, China," Ecol. Eng., vol. 104, pp. 13-22, Jul. 2017, doi: 10.1016/j.ecoleng.2017.03.013

[5] L. Xiu, X. Yao, M. Chen, and C. Yan, "Effect of ecological construction engineering on vegetation restoration: A case study of the Loess Plateau," Remote Sens., vol. 13, no. 8, p. 1407, Apr. 2021, doi: 10.3390/rs 13081407

[6] S. Piao, X. Wang, P. Ciais, B. Zhu, T. Wang, and J. Liu, "Changes in satellite-derived vegetation growth trend in temperate and boreal Eurasia from 1982 to 2006," Glob. Change Biol., vol. 17, no. 10, pp. 3228-3239, 2011

[7] Z. Wen, S. Wu, J. Chen, and M. Lü, "NDVI indicated long-term interannual changes in vegetation activities and their responses to climatic and anthropogenic factors in the Three Gorges Reservoir Region, China," Sci. Total Environ., vol. 574, pp. 947-959, Jan. 2017, doi: 10.1016/j.scitotenv.2016.09.049.

[8] W. Keersmaecker, S. Lhermitte, M. Hill, L. Tits, P. Coppin, and B. Somers, "Assessment of regional vegetation response to climate anomalies: A case study for Australia using GIMMS NDVI time Series between 1982 and 2006," Remote Sens., vol. 9, no. 1, p. 34, Jan. 2017, doi: $10.3390 /$ rs 9010034 .

[9] L. Ulsig et al., "Detecting inter-annual variations in the phenology of evergreen conifers using long-term MODIS vegetation index time series," Remote Sens., vol. 9, no. 1, p. 49, Jan. 2017, doi: 10.3390/rs9010049.

[10] A. S. Hope, W. L. Boynton, D. A. Stow, and D. C. Douglas, "Interannual growth dynamics of vegetation in the Kuparuk River watershed, Alaska based on the normalized difference vegetation index," Int. J. Remote Sens., vol. 24, no. 17, pp. 3413-3425, Jan. 2003 , doi: 10.1080/0143116021000021170.

[11] X. Liu, Z. Tian, A. Zhang, A. Zhao, and H. Liu, "Impacts of climate on spatiotemporal variations in vegetation NDVI from 1982-2015 in Inner Mongolia, China," Sustainability, vol. 11, no. 3, pp. 1-22, 2019 , Accessed: Jun. 05, 2021

[12] K. M. Beurs and G. M. Henebry, "Land surface phenology, climatic variation, and institutional change: Analyzing agricultural land cover change in Kazakhstan," Remote Sens. Environ., vol. 89, no. 4, pp 497-509, Feb. 2004, doi: 10.1016/j.rse.2003.11.006.

[13] C. Alcantara, T. Kuemmerle, A. V. Prishchepov, and V. C. Radeloff, "Mapping abandoned agriculture with multi-temporal MODIS satellite 
data," Remote Sens. Environ., vol. 124, pp. 334-347, Sep. 2012, doi: 10.1016/j.rse.2012.05.019.

[14] S. Piao, X. Wang, P. Ciais, B. Zhu, T. Wang, and J. Liu, "Changes in satellite-derived vegetation growth trend in temperate and boreal Eurasia from 1982 to 2006: Change in vegetation growth over eurasia," Glob. Change Biol., vol. 17, no. 10, pp. 3228-3239, Oct. 2011, doi: 10.1111/j.1365-2486.2011.02419.x.

[15] C. Y. Miao, L. Yang, X. H. Chen, and Y. Gao, "The vegetation cover dynamics (1982-2006) in different erosion regions of the Yellow River Basin, China," Land Degrad. Dev., vol. 23, no. 1, pp. 62-71, Jan. 2012 , doi: $10.1002 / \mathrm{ldr} .1050$

[16] C. F. Olusegun and Z. D. Adeyewa, "Spatial and temporal variation of normalized difference vegetation index (NDVI) and rainfall in the North East Arid Zone of Nigeria," Atmospheric Clim. Sci., vol. 3, no. 4 , pp. 421-426, 2013, doi: 10.4236/acs.2013.34043.

[17] R. B. Myneni, C. D. Keeling, C. J. Tucker, G. Asrar, and R. R. Nemani, "Increased plant growth in the northern high latitudes from 1981 to 1991," Nature, vol. 386, no. 6626, pp. 698-702, Apr. 1997, doi: $10.1038 / 386698 \mathrm{a} 0$

[18] S. Peng et al., "Asymmetric effects of daytime and night-time warming on Northern Hemisphere vegetation," Nature, vol. 501, no. 7465, pp. 88-92, Sep. 2013, doi: 10.1038/nature12434.

[19] A. E. Kelly and M. L. Goulden, "Rapid shifts in plant distribution with recent climate change," in Proc. Natl. Acad. Sci., vol. 105, no. 33, pp. 11823-11826, Aug. 2008, doi: 10.1073/pnas.0802891105.

[20] N. H. Ravindranath, N. V. Joshi, R. Sukumar, and A. Saxena, "Impact of climate change on forests in India," Curr. Sci., vol. 90, no. 3, pp. 354-361, 2006.

[21] V. Joshi and V. Nagare, "Land use change detection along the Pravara River basin in Maharashtra, using remote sensing and GIS techniques," Landsc. Environ., vol. 3, no. 2, Dec. 2009.

[22] A. Rafik et al., "Surface and groundwater characteristics within a semi-arid environment using hydrochemical and remote sensing techniques," Water, vol. 13, no. 3, p. 277, Jan. 2021, doi: $10.3390 / \mathrm{w} 13030277$

[23] G.-M. Tsarouchi and W. Buytaert, "Monitoring land use changes in the Upper Ganga Basin, India by using Remote Sensing and GIS techniques on Landsat 5 TM data," vol. 15, pp. EGU2013-229, Apr. 2013.

[24] R. Sakthivel, M. Manivel, N. Raj, V. Pugalanthi, N. Ravichandran, and V. Anand, "Remote sensing and GIS based forest cover change detection study in Kalrayan hills, Tamil Nadu.," Undefined, 2010.

[25] M. Bouzidi, M. Nouri, Z. Nasr, and S. Khlifi, "Contribution to the assessment of climate change effects on water balance in forest soil: application of the Biljou model to the cork oak forest of Ain Snouss (north-western Tunisia)," Arab. J. Geosci., vol. 13, no. 21, p. 1152, Nov. 2020, doi: 10.1007/s12517-020-06118-8.

[26] M. A. Imaz-Lamadrid, J. Wurl, O. Arizpe-Covarrubias, and E. Romero-Vadillo, "Deterioration of oases subject to climate change and coastal development: The case of Todos Santos Oasis, Baja California Sur, Mexico," Groundw. Sustain. Dev., vol. 11, p. 100401, Oct. 2020 , doi: 10.1016/j.gsd.2020.100401.

[27] S. Ouhamdouch, M. Bahir, D. Ouazar, P. M. Carreira, and K. Zouari, "Evaluation of climate change impact on groundwater from semi-arid environment (Essaouira Basin, Morocco) using integrated approaches," Environ. Earth Sci., vol. 78, no. 15, p. 449, Jul. 2019, doi 10.1007/s12665-019-8470-2.

[28] R. Tiwari, "Analytical study on variation of climatic parameters At Aizawl, Mizoram (India)," 2021.

[29] N. Pettorelli, The Normalized Difference Vegetation Index, Oxford, New York: Oxford University Press, 2014.

[30] M. Dagnachew, A. Kebede, A. Moges, and A. Abebe, "Effects of climate variability on normalized difference vegetation index (NDVI) in the Gojeb River Catchment, Omo-Gibe Basin, Ethiopia," Adv.
Meteorol., vol. 2020, p. e8263246, Jun. 2020, doi $10.1155 / 2020 / 8263246$.

[31] Z. Jiang et al., "Analysis of NDVI and scaled difference vegetation index retrievals of vegetation fraction," Remote Sens. Environ., vol 101, no. 3, pp. 366-378, Apr. 2006, doi: 10.1016/j.rse.2006.01.003.

[32] A. BABQIQI, "Climate change in morocco: case study Marrakech Tensift Al Haouz and implications for agriculture by 2030," Theses, Univ. Cadi Ayyad, Marrakesh, MOROCCMO, 2014.

[33] A. Bensalem, "Vulnerability and adaptation to climate change in the oasis region Tafilalet- Morocco. Doctoral thesis," Theses, Department of Biology, Faculty of Semlalia. Cadi Ayyad, Marrakesh, Morocco, 2014.

[34] F. Fniguire, N.-E. Laftouhi, M. E. Saidi, Z. Zamrane, H. El Himer, and N. Khalil, "Spatial and temporal analysis of the drought vulnerability and risks over eight decades in a semi-arid region (Tensift basin Morocco)," Theor. Appl. Climatol., vol. 130, no. 1-2, pp. 321-330, Oct. 2017, doi: 10.1007/s00704-016-1873-z

[35] Y. A. Brahim, M. E. M. Saidi, K. Kouraiss, A. Sifeddine, and L. Bouchaou, "Analysis of observed climate trends and high resolution scenarios for the 21st century in Morocco," p. 10, 2017.

Copyright $(\odot 2021$ by the authors. This is an open access article distributed under the Creative Commons Attribution License which permits unrestricted use, distribution, and reproduction in any medium, provided the original work is properly cited (CC BY 4.0).

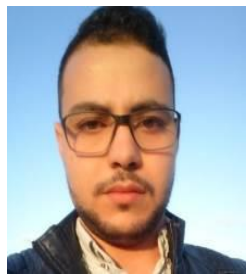

Y. Akensous is a PhD student in Faculty of sciences Ben M'sik, Hassan II University Casablanca, Morocco. He has received a M. S. of GIS and remote sensing, and a bachelor degree in computer science.

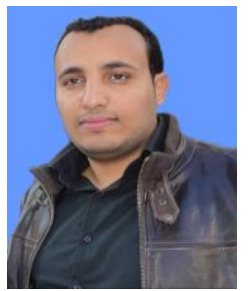

A. Al Sabri is a PhD student in the Department of Physics, Faculty of sciences Ben M'sik, Hassan II University of Casablanca, Morocco, He has received a M. S. electrical engineering, B.S. electronics, electrical engineering, automation and industrial computing, Faculty of sciences Ain Chock, Hassan II University of Casablanca, Morocco.

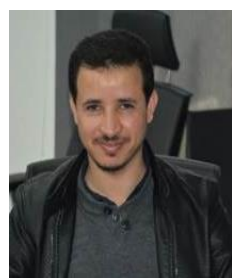

S. Al akad is a PhD student in Faculty of sciences Ben M'sik, Hassan II University Casablanca, Morocco. He has received a M. S. GIS and remote sensing and a professional bachelor degree in computer science.

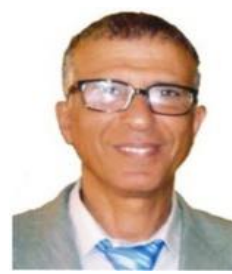

M. Hakdaoui is a professor at the University Hassan II of Casablanca Doctor of the University Pierre et Marie Curie Paris VI in Geomatics, GIS, remote sensing and spatial images processing coordinator of the master of GIS and remote sensing Faculty of Ben M'sik Casablanca. 